\title{
Impacts of Gestational Diabetes Mellitus on the Mother and the Neonate - A Descriptive Study
}

\author{
Sanjoy Kumar Chakraborty ${ }^{1}$, BM Ali Yousuf ${ }^{2}$, Shaikhul Islam³ ${ }^{3}$ Mst. Laila Anjuman Banu ${ }^{4}$, \\ Raziuddin Khan ${ }^{5}$, Khondkar Manzare Shamim ${ }^{6}$, Md. Mesbahuddin ${ }^{7}$
}

\begin{abstract}
Context: Pregnancy complicated by diabetes is a significant medical problem not only affecting maternal health, but also jeopardizing fetal normalcy. Gestational diabetes mellitus (GDM) is a common metabolic disorder that frequently causes maternal and fetal complications. The present study was done to see the impacts of GDM on mother and neonate.
\end{abstract}

Study design: Cross sectional descriptive study.

Place and period of study: Department of Anatomy Chittagong Medical College, Chittagong. From May 2006 to April 2007.

Material: Total number of subjects were seventy, of which 35 were non diabetic pregnant Bangladeshi Bengoli mother (Control group) and 35 were mothers with GDM (GDM group). All GDM mother were under insulin therapy having $\mathrm{HbA1C}$ within $6.5 \%$ to $6.8 \%$.

Method: Relevant data of the mother (Age, weight, gestational period, parity) and the neonate (birth weight, APGAR score) were collected by taking history and hospital record book. APGAR score at $1^{\text {st }}$ minute was taken from the records as determined by the on-duty Anesthetist.

Result: Among the maternal and neonatal variables the mean age, gestational period and parity of the mother were significantly higher in the GDM group than in the Control group $(P=0.01, P=0.00, P=0.01$ respectively). The mean weight of the mother and the mean neonatal birth weight were also higher in the GDM group, but not differ significantly. The mean APGAR score was found to be slightly lower in the GDM group than in the Control group, but the difference was not significant from the statistical point of view.

Conclusion: The present study shows that the GDM may have some adverse impacts on the mother and neonate. Further study with larger sample size having vigorous exclusion criteria is recommended.

Key word: Gestatational Diabetes Mellitus (GDM), Mother, Neonate.

1. Assistant Professor, Department of Anatomy, BGC Trust Medical College, Chittagong.

2. Professor of Anatomy \& Principal, Cox's Bazar Medical College, Cox's Bazar

3. Associate Professor, Department of Anatomy, Chittagong Medical College, Chittagong.

4. Associate Professor, Department of Anatomy, BSMMU, Dhaka.

5. Assistant Professor, Dental Anatomy, Dhaka Dental College, Dhaka

6. Professor and Chairman, Department of Anatomy, BSMMU, Dhaka.

7. Assistant Professor, Department of Anatomy, Kumudini Women's Medical College, Tangail.

Correspondence: Dr. Sanjoy Kumar Chakraborty

\section{Introduction:}

Among the different types of diabetes mellitus, gestational diabetes mellitus is an important type as it involves the expecting mother, and thus two lives are involved. GDM has higher prevalence rate, involved $7 \%$ of all pregnant women in Euro-Amarican population ${ }^{1} \& 3.8 \%$ of African pregnant women according to WHO criteria ${ }^{2}$. The incidence of GDM in Bangladesh is $6.7 \%$ among all Bangladeshi Bengoli pregnant mothers ${ }^{3}$.

Elderly mother suffers more commonly from GDM than young mother. Many studies abroad showed 
that maternal age was significantly higher in the Impaired gestational glucose tolerance (IGGT) and GDM group than in the control group ${ }^{4,5}$. In a study Sumaksri et al. ${ }^{6}$ showed that the incidence of GDM in pregnant mother aged 30-34 years old was found to be $5.7 \%$.

In many studies significant difference were found in maternal body weight of diabetic and healthy normal mother ${ }^{4,5}$. Colditz et al. ${ }^{7}$ reported that relative risk of developing diabetes was 3.6 times higher among women having average body mass index 23-23.9 $\mathrm{kg} / \mathrm{m}^{2}$ and incidence was found to be less having body mass index less than $22 \mathrm{~kg} / \mathrm{m}$.

Parity of mother was found to be significantly higher in GDM group as compared to the control group as reported by Makhseed et al ${ }^{4}$. GDM, maternal obesity, increasing age and higher parity are main risk factors for fetal macrosomia ${ }^{8}$. Studies at home and abroad showed association between mother having GDM and fetus having macrosomia or being large for gestational age (LAG) $4,9,10,11$.

Though, Svare et al. ${ }^{12}$ found a higher frequency of macrosomia but the difference was not statistically significant in the GDM than in the Control group $(8 \% \text { vs } 2 \%, P=0.07)^{11}$. Gillman et al. ${ }^{13}$ have considered the greater neonatal high birth weight found in the case of maternal GDM to be associated with metabolically altered fetal environment caused by $\mathrm{GDM}^{13}$.

APGAR score is an important indicator of perinatal morbidity. Asphyxia and transient tachypnia were found to be two to three times higher in the GDM group than in the normal with resultant decrease of APGAR score in the babies of GDM group as reported by Persson et al. ${ }^{14}$, but perinatal morbidity was reduced in well treated gestational diabetic mother as mention by Crowther et al. ${ }^{15}$. However, in a study on Bangladeshi Bengoli pregnant women did not find any significant difference in maternal age, weight, gestational age, parity, neonatal birth weight and APGAR score, reported by Alam et al. ${ }^{13}$.

\section{Materials:}

Total number of subjects were seventy, of which 35 were non diabetic pregnant Bangladeshi Bengoli mother (Control group) and 35 were mothers with GDM (GDM group). All GDM mothers were under insulin therapy having $\mathrm{HbA} 1 \mathrm{C}$ within $6.5 \%$ to $6.8 \%$.

\section{Methods:}

Relevant data of the mother (age, weight, gestational period, parity) and the neonate (birth weight, APGAR score) were collected by taking history and hospital record book. APGAR score at $1^{\text {st }}$ minute was taken from the records as determined by the on-duty anesthetist. Mother having pre-GDM, hypertension, pre-eclampsia, eclampsia, delivery of multiple babies in the present pregnancy were excluded from the study.

\section{Results:}

Among the maternal and neonatal variables the mean age, gestational period and parity of the mother were significantly higher in the GDM group than in the control group $(P=0.01, P=0.00, P=$ 0.01 respectively). The mean weight of the mother and the mean neonatal birth weight was also higher in the GDM group, but did not differ significantly. The mean APGAR score was found to be slightly lower in the GDM group than in the control group, but the difference was not significant from the statistical point of view. The results are shown in the Table - I, II and Figure - 1, 2, 3, 4, 5.

Table-I

Mother's variables in the two groups

\begin{tabular}{lccc}
\hline Variable & $\begin{array}{c}\text { Control } \\
\mathrm{n}=35\end{array}$ & $\begin{array}{c}\mathrm{GDM} \\
\mathrm{n}=35\end{array}$ & $\begin{array}{c}\text { Significance } \\
\text { of difference }\end{array}$ \\
\hline $\begin{array}{l}\text { Mother's age } \\
\text { (years) }\end{array}$ & & & \\
Range & $20-32$ & $22-40$ & $\mathrm{~S}$ \\
Mean \pm SD & $24.72 \pm 3.72$ & $27.96 \pm 4.71$ & $(\mathrm{P}=0.010)$ \\
Weight (kg) & & & \\
Range & $50-70$ & $52-80$ & $\mathrm{NS}$ \\
$\begin{array}{l}\text { Mean } \pm \text { SD } \\
61.56 \pm 4.81\end{array}$ & $63.92 \pm 6.66$ & $(\mathrm{P}=0.158)$ \\
Gestational & & & \\
period(wk) & $38-40$ & $36-40$ & $\mathrm{~S}$ \\
$\begin{array}{l}\text { Range } \\
\text { Mean } \pm \text { SD }\end{array}$ & $38.88 \pm 0.52$ & $38 \pm 0.95$ & $(\mathrm{P}=0.000)$ \\
$\begin{array}{l}\text { Parity } \\
\text { Range }\end{array}$ & $0.80 \pm 0.70$ & $1.44 \pm 1.08$ & $(\mathrm{P}=0.017)$ \\
Mean \pm SD & & $0-4$ & $\mathrm{~S}$ \\
\hline
\end{tabular}

Student's $\mathbf{t}$ test was done to find out the differences in the variables between the two groups. $\mathrm{P} \leq 0.05$ was considered as the level of significance. NS: Not significant. S: Significant. 


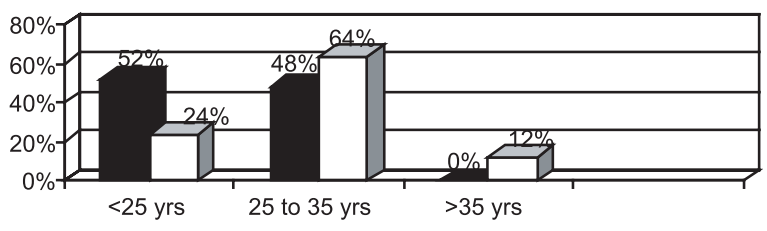

Control group $\quad \square$ GDM group

Fig.-1: Multiple bar diagram showing the percentage frequencies of various categories of maternal age in the two groups.

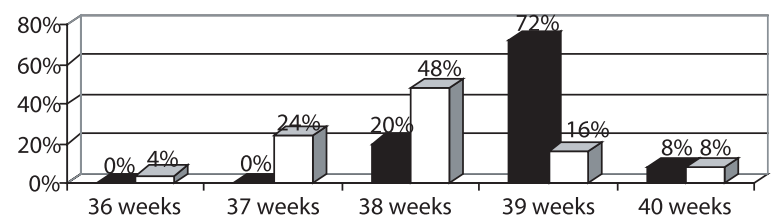

- Control group $\square$ GDM group

Fig.-3: Multiple bar diagram showing the percentage frequencies of various categories of gestational age in the two groups.

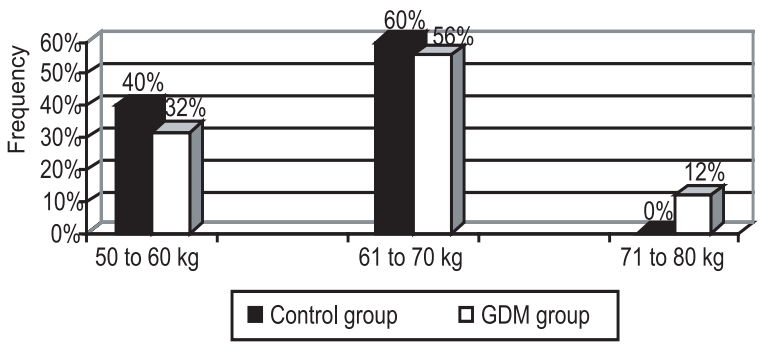

Fig.-2: Multiple bar diagram showing the percentage frequencies of various categories of maternal weight in the two groups.

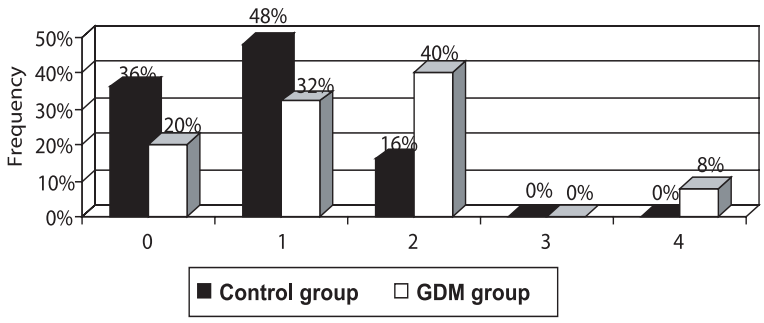

Fig.-4: Multiple bar diagram showing the percentage frequencies of various categories of parity of the mother in the two groups.
Table-II

Neonatal variables in the two groups

\begin{tabular}{lccc}
\hline Variable & $\begin{array}{c}\text { Control } \\
\mathrm{n}=35\end{array}$ & $\begin{array}{c}\text { GDM } \\
\mathrm{n}=35\end{array}$ & $\begin{array}{c}\text { Significance } \\
\text { of }\end{array}$ \\
\hline Birth weight $(\mathrm{kg})$ & & & \\
Range & $2.5-3.8$ & $2.4-4.0$ & $\mathrm{NS}$ \\
Mean \pm SD & $3.09 \pm 0.35$ & $3.26 \pm 0.40$ & $(\mathrm{P}=0.126)$ \\
APGAR score in & & & \\
1st minute & $8-10$ & $8-10$ & $\mathrm{NS}$ \\
Range & $9.12 \pm 0.72$ & $9.04 \pm 0.79$ & $(\mathrm{P}=0.711)$ \\
Mean \pm SD & 9 & &
\end{tabular}

Student's t test was done to find out the differences in the department of the variables between the two groups.

$\mathrm{P}=0.05$ was considered as the level of significance. NS: Not significant.

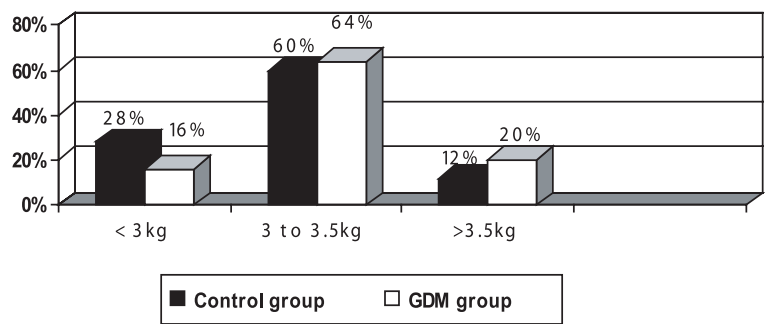

Fig.-5: Multiple bar diagram showing the percentage frequencies of various categories of neonatal birth weight in the two groups.

\section{Discussion:}

In the present study, the mean maternal age was significantly higher in the GDM group than in the control group $(P<0.05)$. Makhseed et al. ${ }^{4}$ and $\mathrm{Di}$ Cianni et al. ${ }^{5}$ showed similar trend in the IGGT group and the GDM group than in the control group. Though, Alam et al. ${ }^{3}$ showed non-significant variation in maternal age between GDM, Pre-GDM \& control group in Bangladesh. Whether there is any relationship between the age and the GDM is not clearly understood, but most of the mothers in the present study were from rural area and it might be possible that the mother with untreated GDM in previous pregnancies were likely to have frequent miscarriages which in turn could have increase the maternal age in the GDM group. 
Though the mean maternal weight was found to be higher in the GDM group as compared to the control group but it did not differ significantly between the two groups $(P>0.05)$. A general belief regarding the incidence of diabetes mellitus is that there is a strong association between gestational diabetes and maternal obesity. Different studies showed significantly greater maternal weight in the GDM mothers ${ }^{4,5}$. Contrary to this concept, the present study did not show any significant difference in the weight of the mother in the GDM group as compared to the control group. It is well known fact that Diabetic patient usually lose their weight, but those who get insulin therapy normally regain weights as insulin is an anabolic hormone. As all the mothers selected in the present study were under insulin therapy, so it might be possible that insulin have an effect in increasing the weight of the mother in the GDM group. Alam et al. ${ }^{3}$, reported a similar result among diabetic group too.

In the GDM group more than $75 \%$ cases had a gestational period varying between 36 and 38 weeks, though in the Control group more than $90 \%$ cases had gestational age varying between 38 and 40 weeks. Thus the mean gestational age of the GDM and the Control group differed significantly $(P<$ 0.001). Early caesarean section within 36 to 38 weeks in the GDM group might have been the possible cause in the present study.

In the present study the mean parity of the mother also differed significantly between the GDM and the control group $(P<0.05)$. Thus the present study had a similar accord with the result of Makhseed et al. ${ }^{4}$, who also found a significantly higher parity in IGGT group as compared to the control group ${ }^{3}$. As most of the mothers in the present study were coming from rural area, it might be possible that lack of awareness and proper treatment of mother in the GDM had frequent miscarriages or stillbirth in the previous pregnancies. This might be the possible explanation of higher parity in the GDM group. However, Alam et al. ${ }^{3}$ did not find any significant difference of parity in their study on Bangladeshi population. The possible explanation is that as they selected all mothers from BSMMU hospital and BIRDEM hospital, most them were affluent, aware and under proper treatment, and therefore, the chance of complications of GDM were lower in them.

The mean neonatal birth weight in the GDM group was higher than the Control group, but the difference was not statistically significant $(P>0.05)$. Though, many studies at home and abroad showed significant association between GDM and fetal macrosomia or large for gestational age $e^{4,, 9,10}$. But Svare et al. ${ }^{12}$ in abroad and Alam. ${ }^{3}$ in Bangladesh reported a non significant higher frequency of macrosomia or LAG in the GDM group than in the Control group ${ }^{3,12}$. The result of the present study had the similarity with above studies too. The possible explanation is that with the advent of modern obstetric care, increase awareness of people regarding GDM and well treatment of gestational diabetic mother with insulin, the incidence of macrosomia and other serious perinatal morbidity has been much reduced but the incidence of LAG babies still remain little high.

APGAR score was recorded in the present study to have an idea about possible impacts of GDM on the fetus / neonate. APGAR score was recorded at $1^{\text {st }}$ minute after birth; the score was more or less similar in the GDM and the Control groups and did not show any significant difference between the two groups. Similarly, in a study by Alam. ${ }^{14}$ on PreGDM and GDM groups, the APGAR score at $1^{\text {st }}$ and $5^{\text {th }}$ minute did not show any significant difference with the Control group. On the other hand, Persson et al. noted that, asphyxia and transient tachypnea were two to three times higher in the GDM group than in the normal group with resultant decrease in the APGAR score in the GDM group ${ }^{14}$. It may be investigated wheather increase awareness about diabetes leading to regular prenatal check up and proper treatment of gestational diabetes in the GDM mothers of the present study is responsible for reduction in serious perinatal complications and thereby, for near normalcy of APGAR score in the present study.

\section{Acknowledgement:}

We express our deepest sense of gratefulness to those mothers and babies who were the subjects of our study and without whom this study would not have been possible. 


\section{References:}

1. Farrell M. Improving the care of women with gestational diabetes mellitus. Am J Matern Child Nurs 2003; 28: 301-15.

2. Ranchod HA, Vanghan JF, Jarris P. Incidence of gestational diabetes at Northdale Hospital, Pietermaritzburg. S Afr Med J 1991; 80: 1416.

3. Alam MR. Gross and Histomorphologic study of Umbilical Cord in Pre-gestational diabetes mellitus and gestational diabetes mellitus (thesis). BSMMU: Bangladesh; 2006.

4. Makhseed MA, Ahmed MA, Musini VM. Impaired gestational glucose tolerance. Its effect on placental pathology. Saudi Med J 2004; 25: $1241-44$.

5. Di Cianni G, Volpe L, Lencioni C, Miccoli R, Cuccuru I, Ghio A, et al. Prevalence and risk factors for gestational diabetes assessed by universal screening. Diabetes Res Clin Pract 2003; 62: 131 - 37.

6. Sumeksri P, Wongyai S, Aimpun P. Prevalence of gestational diabetes mellitus in pregnant women aged 30 to 34 years old at phramongkutklao Hospital. J Med Assoc Thai 2005; 89: 94 - 99.

7. Colditz GA, Willett WC, Stampfer MJ, Manson JE, Hennekens $\mathrm{CH}$, Arky RA, et al. Weight as a risk factor for clinical diabetes in women. Am J Epidemiol 1990; 32: 501 - 13.
8. Mathew M, Machado L, Al-Ghabshi R, AlHaddabi R. Fetal macrosomia: risk factor and outcome. Saudi Med J 2005; 26: 96 -100.

9. Khatun N, Latif SA, Uddin MM. Infant outcome of gestational diabetes mellitus. Mymensingh Med J 2005; 14: 29-31.

10. Ehrenberg HM, Mercer BM, Catalano PM. The influence of obesity and diabetes on the prevalence of macrosomia. Am J Obstet Gynecol 2004; 191: 964-68.

11. Jensen DM, Sorensen B, Feilberg-Jorgensen $\mathrm{N}$, Westergaard JG, Beck-Nielsen H. Maternal and perinatal outcomes in 143 Danish women with gestational diabetes mellitus and 143 controls with a similar risk profile. Diabet Med 2000; 17: $281-86$.

12. Svare JA, Hansen BB, Molsted-Pedersen L. Perinatal complications in gestational diabetes mellitus. Acta Obstet Gynecol Scand 2001; 80: 899-904.

13. Gillman MW, Rifas-Shiman S, Berkey CS, Field AE, Colditz GA. Maternal gestational diabetes, birth weight, and adolescent obesity. Pediatrics 2003;111: 221-26.

14. Persson B, Hanson U. Neonatal morbidities in gestational diabetes mellitus. Diabetes Care 1998; 21: $879-84$.

15. Crowther CA, Hiller JE, Moss JR, McPhee AJ, Jeffries WS, Robinson JS, et al. Effect of treatment of gestational diabetes mellitus on pregnancy outcomes. N Engl J Med 2005; 352: 2477-86. 